\title{
Feeding Induced in Cats by Electrical Stimulation of the Brain Stem*
}

\author{
By \\ WANDa Wyrwicka and Robert W. Doty \\ Department of Physiology, University of Michigan, Ann Arbor, Michigan
}

Received October 11, 1965

\begin{abstract}
Summary. Stimulation at 14 of 106 loci (Figs. 1 and 2) at which electrodes had been chronically implanted elicited immediate feeding in fully satiated, freely moving cats. Half of the effective points were in the lateral hypothalamus and thus agreed with expectations from extensive prior research on the neural organization of feeding behavior. The other points, however, were in the ventral tegmental area or at the ventrolateral boundary of the central gray. The distribution of all effective points could be explained as following a projection pathway from the globus pallidus. Exploration along 162 recording tracks in acute experiments on these same cats revealed no consistent differences in projection of evoked potentials which could distinguish stimulation at effective versus ineffective loci. Potentials of possible significance, however, were evoked in the paramedial nucleus reticularis of the medulla, the rostral pontine nuclei, the nucleus centralis superior of Bekterev, the lateral frontal cortex and the basal medial forebrain in the vicinity of the diagonal band of Broca.
\end{abstract}

Key Words: Feeding - Electrical stimulation - Brain stem.

\section{Introduction}

The fact that electrical stimulation of the brain can mimic the action of natural stimuli in eliciting highly complex yet stereotyped behaviors, such as fleeing, attack or feeding, offers some possibility of identifying and studying by this means the neural systems and processes involved in the organization of these goaldirected activities.

For feeding behavior, analyses performed on rats have consistently shown that it is possible to produce immediate intake of food upon electrical stimulation of the lateral hypothalamus ${ }^{17,23,24,28,33,38}$. Corollary experiments demonstrate that bilateral lesions in this same area produce aphagia $2,20,27,32,38$. Immediate feeding has also been elicited in rats by stimulation of the mamillary body ${ }^{22}$, and with macaques as well, feeding is elicited by stimulation in a number of loci in addition to the lateral hypothalamus ${ }^{31}$. In cats ${ }^{7,16}$ and goats $^{21}$ hypothalamic stimulation has produced not only feeding but efforts to eat inedible material. Such effects were also seen with stimulation of the dorsal motor nucleus of the vagus ${ }^{21}$, but

* Supported by USPHS Grant B 1068. Dr. WyrwICKa held a fellowship from Foundations' Fund for Research in Psychiatry. The authors are indebted to Mr. Josepe Jones and Mrs. Frances Bignall for technical assistance. 
appropriate hypothalamic stimulation in goats can evoke instrumental alimentary conditioned reflexes ${ }^{40}$. Prolonged hypothalamic tetanization in cats may greatly augment subsequent food intake even though none occurs during stimulation ${ }^{9}$. Lateral hypothalamic lesions in cats and monkeys also produce aphagia ${ }^{4}$.

Most of this evidence suggests that a major part of the organization of feeding behavior occurs in the lateral hypothalamus. It is equally obvious, however, that the hypothalamus cannot alone organize feeding behavior in its entirety. Extending our preliminary report ${ }^{41}$, the present experiments attempt to specify some of the pathways over which such a hypothalamic "feeding center" might exert influences upon or receive influences from other areas of the brain. It is tentatively suggested that the major descending pathway approximates the course of the pallido-incerto-tegmento-olivary tract ${ }^{39}$ at least through the mesencephalic level, and that a strong projection may be present from the "feeding center" into the basal medial forebrain around the diagonal band of Broca.

\section{Method}

Six pairs of electrodes were implanted aseptically, three on each side of the brain stem, in each of 24 cats. The electrodes were made from $0.32 \mathrm{~mm}$-diameter platinum-plated nichrome wires placed side by side with uninsulated, sharpened tips separated by about $1 \mathrm{~mm}$. They were connected by screws to a plastic terminal block ${ }^{10}$.

Tests of the effect of stimulating the various brain stem regions were begun several days after surgery. The animal was habituated, for several days if necessary, to a sound-insulated chamber of about $1 \mathrm{~m}^{2}$ floor space, and was observed through a one-way-vision mirror. It was allowed to eat and drink to satiety in the chamber and then, in most experiments, was provided with three bowls filled respectively with water, milk and its favorite food. When the animal had removed itself for some minutes from the food and was obviously no longer interested in feeding (e.g., it was grooming itself or lying down, etc.) electrical stimulation was applied to one electrode pair for $10 \mathrm{sec}$ to $1.5 \mathrm{~min}$. A Grass S-4 stimulator with isolation unit coupled to a constant current converter ${ }^{6}$ was used to generate rectangular pulses, $0.05-0.6 \mathrm{~mA}$ (usually $0.1-0.2 \mathrm{~mA}$ ), 1-msec pulse duration, 50/sec. Stimulus current was monitored continuously with an oscilloscope. Changes in behavior, if any, were noted and after a few minutes stimulation was repeated with further adjustment of intensity, frequency, arrangement of polarity or use of another electrode pair. Such experimental sessions lasted up to 1.5 hrs. Each electrode pair was used on at least two different days.

An acute experiment was performed terminally on 15 of the animals used in the behavioral studies. Feeding behavior had been consistently elicited in $\mathbf{1 l}$ of these eats. Under Surital anesthesia (a short-acting barbiturate) the innervation of the orbital, dental and aural areas was carefully infiltrated with xylocaine, and the cat placed in a stereotaxic frame. All cut skin was saturated with benzocaine spray, craniotomies were performed and the dura mater cut. Flaxedil was then substituted for Surital, as necessary, through an intravenous cannula. Body temperature was maintained above $35^{\circ} \mathrm{C}$. Three of the subcortical areas which had been studied behaviorally were stimulated individually with $0.1 \mathrm{msec}, 10 \mathrm{~V}$ pulses, $0.3 / \mathrm{sec}$, while two pairs of recording electrodes were moved in 1-mm steps through the brain. The "bipolar" arrangement was used for both stimulation and recording. From 2-24 recording tracks were made in each animal, usually ipsilateral to the stimulating electrodes. Responses were recorded with Grass P-4 preamplifiers, a Tektronix 502 dual-beam oscilloscope and a Grass kymograph camera. Control experiments indicated that the intensity of stimulation with the shorter pulses used in the acute experiments was comparable in effect to the lower intensities and longer pulses used in the behavioral situation.

All cats were anesthetized and perfused with saline followed by $10 \%$ formalin. Brains were embedded in paraffin, sectioned serially at $20 \mu$, stained by the Weil and Nissl techniques, and studied for localization of electrode positions. Locations cited in the text refer to the stereotaxic atlas of $J_{A S P E R}$ and AJMONE-MARSAN ${ }^{18}$. 


\section{Results}

Behavioral data. Histological and behavioral information is adequate for 106 electrode pairs (Figs. 1 and 2). For 14 of these the major, consistent behavior

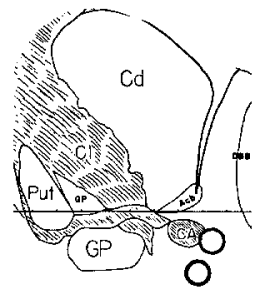

A 15.5

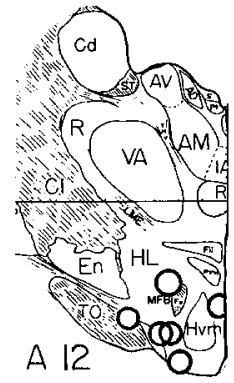

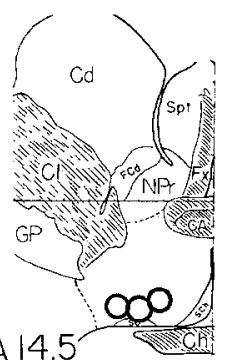

A 14.5 .

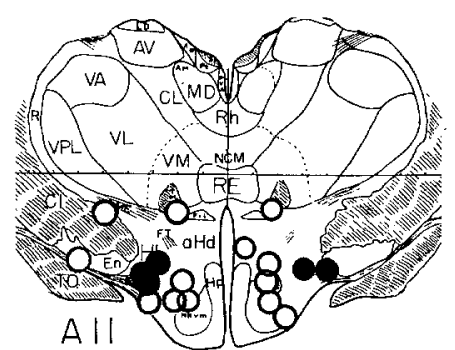

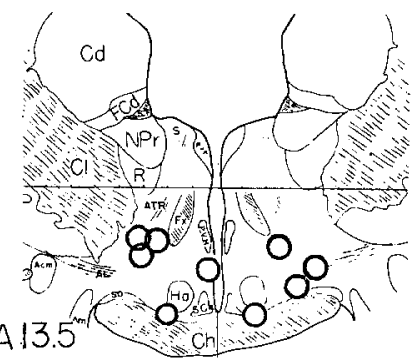

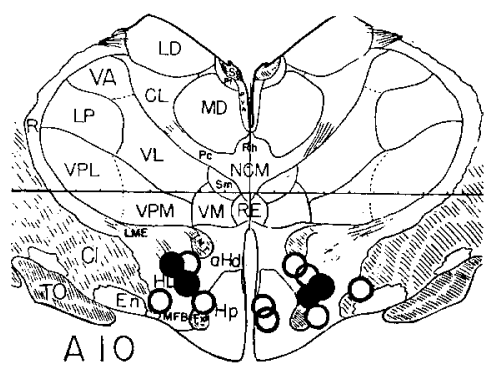

Fig. 1
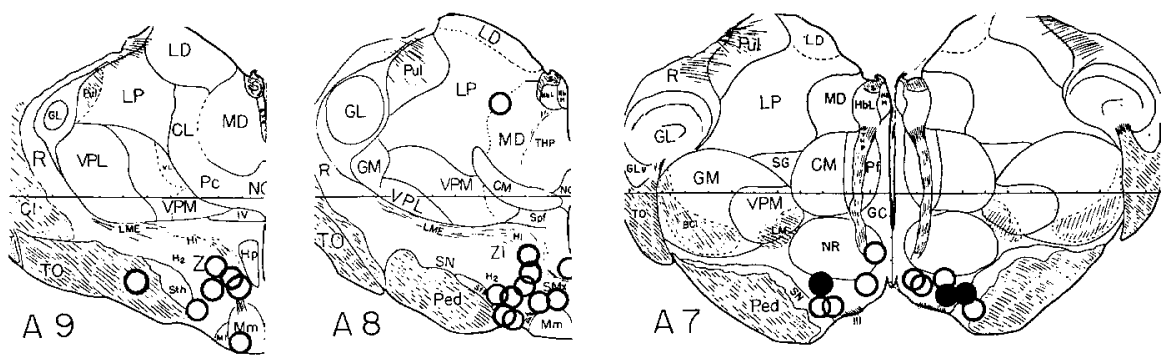

Fig. 2
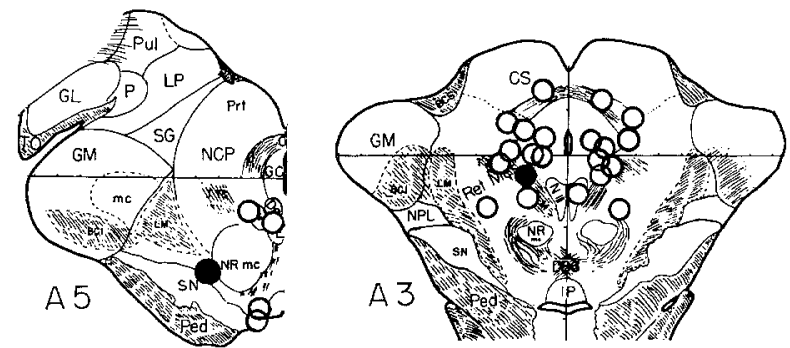

Figs. 1 and 2, Histologically confirmed location of 106 chronically implanted stimulating electrodes for which the elicited behavior was adequately studied in 21 freely moving cats. Filled circles; "effective points", i.e., consistent elicitation of feeding with a lateney less than 30 sec; open circles: "ineffective points", i.e., absence of consistent feeding behavior. Points at A 6, 4 and 2 have been placed to the best approximation 1 mm anterior or posterior

evoked by stimulation in the fully satiated state was that of repeatedly seeking and eating food or drinking milk within $\mathbf{3 - 3 0}$ sec after stimulus onset. Currents 
of $0.1-0.2 \mathrm{~mA}$ with pulses at $50 / \mathrm{sec} 1.0$ - msec pulse duration, were required for this effect. This level of intensity is comparable to that required for elicitation of other non-feeding effects from the subcortical areas explored.

When feeding is elicited by stimulation at anterior levels (A 10-A 12, Fig. 1), it ceases when the stimulation is shut off; but with more posterior placements (A 7-A 2, Fig. 2) there is a tendency for feeding to continue for some time (up to a few minutes) beyond the stimulation. As "forced" feeding continued during the course of the observations and the animal became more and more satiated, there was some slackening in the intensity of the feeding behavior elicited by stimulation of an effective point. The latency between onset of stimulation and start of feeding would then lengthen, but increasing the stimulus intensity by $0.1 \mathrm{~mA}$ could then restore the feeding activity to its original level. The effectiveness of stimulation nevertheless was greatly affected by the animal's general appetite for food. For instance a sick cat which would not eat on a particular day could not be induced to do so upon stimulation of a previously or subsequently effective electrode pair. Cats which prefer milk for most of their diet, drink milk upon stimulation. On one occasion when intense eating of meat was being induced repeatedly in Cat 971 by stimulation at $0.25 \mathrm{~mA}$ of the $\mathrm{A} 11, \mathrm{~L} 3,-3$ area, the meat in the bowl was replaced with a banana. Upon stimulation the cat quickly approached the bowl, sniffed the banana, turned away (in some disgust and frustration!?), searched the chamber, returned to the banana, etc., but would not eat the banana. With the parameters employed in these experiments the bulimia seen by Hess ${ }^{16}$ was not obtained.

Stimulation at the points from which feeding behavior was elicited in some instances produced other "forced" movements. This was particularly true for electrodes in the ventral tegmentum, which produced a typical "tegmental reaction" of head rotation upward together with strong circling movements. Because of these interfering movements such animals were unable to eat if higher intensity currents were used, but could overcome this motor handicap and get to the food or milk at lower current strengths or lower frequencies. There was no type of movement common to the various points from which feeding was elicited nor which distinguished effective from ineffective points relative to feeding.

Orienting and investigatory responses were elicited by $0.1-0.2 \mathrm{~mA}$ stimulation at most of the points in Figs. 1 and 2. This was often accompanied by sniffing or licking and occasionally the animal would eat a bite or two during the course of its exploratory behavior. This occasional eating was more likely to occur with stimulation of areas labelled "ineffective" in Fig. I which were close to areas found effective in other cats; or during the early part of a session when the degree of satiety was perhaps minimal. Considerable care was taken to distinguish this occasional but irregular eating from the reliably reproducible eating obtainable by stimulation of points labelled "effective" in Figs. 1 and 2. Continuous rhythmic licking was elicited from the medial edge of the peduncle in two cats. Drinking of water was never seen, but perhaps this is not unexpected for cats maintained on a moist diet.

A general feeling for the procedures and results of these experiments can be gained from the following typical protocol. 
Cat $A-F 4$, August 2, 1961:

Point 1 (medial effective point, right side of Fig. 1, A-11) 15:10.0.1 mA (all stimuli 50/sec, 1 -msec pulses, on for $20 \mathrm{sec}$ ). Sniffs floor. $-0.2 \mathrm{~mA}$. Comes to food and eats after 10 sec. -0.2 $\mathrm{mA}$. Immediately to food and eats after 3 sec. Stops immediately when stimulus off. Does not
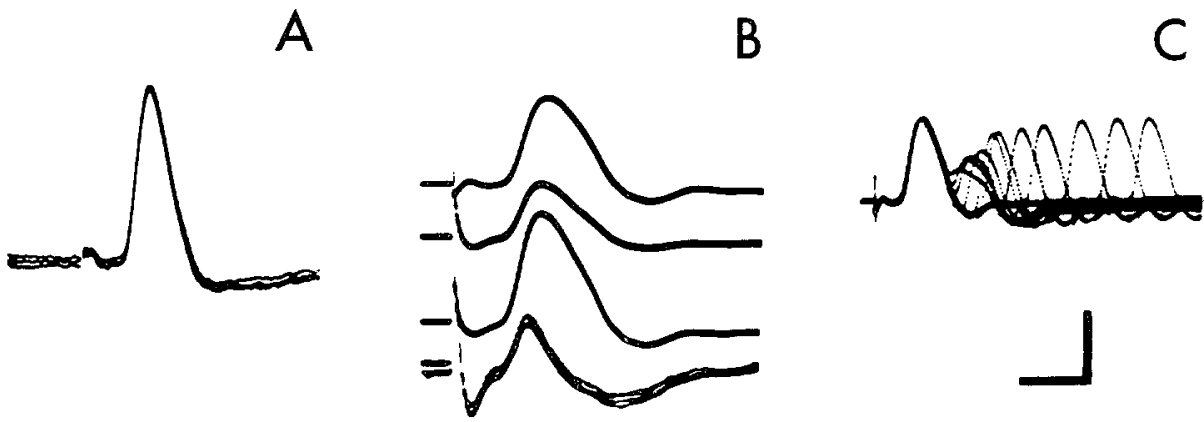

Fig. 3. A, response at A $17, \mathrm{R} 2,1.5 \mathrm{~mm}$ above base of brain, "bipolar" recording, to stimulation (0.01-msec pulse, $6 \mathrm{~V}$ ) of contralateral "effective" point in ventral tegmental area of Tsai (filled circle on left, A 7, Fig. 2). Threshold $1.5 \mathrm{~V}$, latency $0.7 \mathrm{msec}$. Calibration: $400 \mu \mathrm{V}, 1 \mathrm{msec} . B$ and $C$, another preparation, urethane anesthesia; stimulation and recording as in $A$. In $B$ upper trace is "bipolar" record, then upper and deep electrodes of recording pair and, lowest trace, cortex of coronal gyrus, referred to frontal bone; upward deflection positive. Calibration from above down: $400,1000,1000$ and $100 \mu \nabla$, i.e. response greatest from electrode near base of brain; time, 1 msec. $C$ same as upper trace of $B$, second stimulus at varying intervals showing response about 90 per cent recovered within 3 msec; calibration, 2 msec

eat in interval between stimulations. - 15:25. Stimulus polarity reversed (SPR) $0.1 \mathrm{~mA}$. Orienting reaction, slight restlessness, walks about and sniffs walls. $0.2 \mathrm{~mA}$. Restless, goes to meat bowl, then "runs" about in the chamber.

Point 2 (second most dorsal point, Fig. 2, A 8) 15:28. 0.1 mA. Sniffs food. Restless, tries to climb wall (escape ?). Stimulus off within 10 sec. - SPR. $0.1 \mathrm{~mA}$. After 5 sec goes to bowl, but does not eat. Looks at wall and crouches.

Point $1.0 .2 \mathrm{~mA}$. Eats after $3 \mathrm{sec}$. Stops immediately when stimulus off.

Point 3 (medial point near left fornix, Fig. 1, A 13.5) 15:40. $0.1 \mathrm{~mA}$. Looks around. Licks nose $-0.2 \mathrm{~mA}$. Looks around at food and at walls. Has appearance of strong investigatory reaction. - SPR. $0.2 \mathrm{~mA}$. Similar looking around, crouches. Sniffs food, but does not eat. $0.2 \mathrm{~mA}$. Same; restless.

Point 4 (in origin of mamillothalamic tract, most medial dorsal point, Fig. 2, A 9) 15:46. $0.1 \mathrm{~mA}$. Scratches at door. $-0.2 \mathrm{~mA}$. Tries to escape at door. Stimulus off in $10 \mathrm{sec}$ - SPR. $0.1 \mathrm{~mA}$. Licking nose. After $20 \mathrm{sec}$ comes to bowl but does not eat, looks around. $-0.2 \mathrm{~mA}$. Approaches bowl after 12 sec, but no eating.

Point 5 (posterior commissure, most dorsal point on left, Fig. 2, A 3) 16:06. 0.1 mA. Licks nose. Lies down beside bowls, but restless. - $0.1 \mathrm{~mA}$. Head turns to right and up. Rather quiet. $-0.2 \mathrm{~mA}$. Head turns right, held after stimulus off. - SPR. $0.2 \mathrm{~mA}$. Restless. Head turning to right. Escape reaction, violent movements, stimulus off within a few seconds.

Point 6 (above posterior commissure outside of neural tissue). Stimulated three times, no significant reaction.

Point 1. 16:34. 0.2 mA. Walks quickly to bowl, eats. Leaves bowl, walks about, returns and eats. $-0.15 \mathrm{~mA}$. Eats after $10 \mathrm{sec}$ but restless. - $0.15 \mathrm{~mA}$. Eats after $3 \mathrm{sec}$.

Acute experiments. A total of 162 recording tracks were made in the forebrain anterior to the chiasm, and in the medulla, pons and posterior basal mesencephalon. In addition, the dorsal surface of the frontal cortex was explored. No consistent pattern of projection was found to distinguish responses to stimulation of points previously shown effective versus those ineffective in the elicitation of feeding. The potentials described below could be evoked by stimulation in hypothalamic or basal mesencephalic areas from which feeding was not produced, but all were 
evoked in at least two animals by stimulation at points from which feeding had been induced.

Stimuli at the "A 11, L 3" area evoked potentials in the ventral tegmental area of $T s a i^{35}$ beneath nucleus ruber. The major response had a latency of $5-10 \mathrm{msec}$, but was preceded by smaller spikes. Both the "A 11, L 3" area and the area of Tsai projected into the paramedial nucleus reticularis of the medulla, the rostral pontine nuclei and nucleus centralis superior of Bekterev with a latency of about $1.0-1.5$ msec.

Stimuli in the vicinity of the mammillo-thalamic tract evoked prominent potentials in the anterior cingulate and even orbital cortex with a latency of 2.5 to $3.5 \mathrm{msec}$. Similar potentials (surface-positive) were evoked in dorsolateral frontal cortex from many hypothalamic loci and also from the effective point bordering the central gray at A 3 (Fig. 2).

From both the A 11, L 3 area and the area of Tsai very large potentials could be elicited in the ipsilateral olfactory tubercle in the vicinity of the diagonal band of Broca (Fig. 3). The latency was only $0.7-1.0 \mathrm{msec}$. Since this spike was not usually followed by further action, recovered rapidly (Fig. 3C), and could be obtained under barbiturate anesthesia, it might be inferred to arise from fibers of passage. Stimulation in the basal medial forebrain area, however, did not elicit significant potentials at the hypothalamic or tegmental points. The responsive area encompasses at the least that bounded by the coordinates A 15-18, L $1-3$, -1 to -4 .

\section{Discussion}

The most difficult question to answer in experiments of this type is whether stimulation at a given anatomical locus would elicit the same behavior inherently in all individuals, or whether the behavior obtained may instead be significantly dependent upon vagaries in the past and present experience of the individual animal ${ }^{11}$. The extensive distribution of points from which the same behavior may be elicited, as seen in the present experiments or those of HESS ${ }^{16}$ or RoBINSON and MismkL ${ }^{31}$, together with great overlap among areas from which many different behaviors are elicited in different individuals ${ }^{16,31}$ renders unconvincing most efforts at constraining the data within "an anatomical system". It might also be expected that the introduction of tetanic stimuli directly among the neurons organizing a particular behavior should lead to disruption rather than elicitation of this behavior.

Despite these shortcomings in interpretation the present data conform reasonably well to what might be expected from a "feeding center" in the lateral hypothalamus. The five electrode pairs in the A 11, L 3, - 3.5 region all elicited feeding behavior. Stimulation of points bordering this area sometimes produced unstable feeding responses. All the effective points (Fig. 1) lie lateral to all of those reported by BRÜGGER and $\mathrm{HESS}^{16}$; but on the other hand the behavior studied in the two sets of experiments may be different since at no time did we observe the attempts to eat inedible objects, so typical in Hess' data. The location of effective points in the lateral hypothalamus shown in Fig. 1 does agree with that for elicitation of 
feeding effects in the few other cats reported ${ }^{3,9,13}$, and with that found effective in rats $^{38}$ and goats 21,40 .

However, the immediate induction of feeding by stimulation in the ventral tegmental area of $\mathrm{TSAI}^{35}$ or near the central gray (Fig. 2) significantly changes the scope of the problem. Except for some tendency for feeding to continue after cessation of stimulation at these more posterior points, there is apparently no essential difference in feeding behavior elicited from posterior versus anterior areas. An effective point in the Tsai area was also found in one goat by LARsson ${ }^{21}$. The points lie roughly along the course of the pallido-incerto-tegmento-olivary system described in macaques by Woodburne et al. ${ }^{39}$. Although MorgaN ${ }^{25}$ did not find a pallidal projection to the ventral tegmental area in cats, JoHsson and Clemente ${ }^{19}$ apparently did. Stimulation at effective lateral hypothalamic points, all of which lay closely within the debouchment of the ansa lenticularis into the hypothalamus (Fig. 1), evoked potentials in the Tsai area. Stimulation of the globus pallidus also blocks the dramatic sinusoidal rhythms seen in the ventral tegmental area during barbiturate anesthesia ${ }^{34}$.

It is thus reasonable to suggest that the "feeding center" may exist as much in the globus pallidus as in the lateral hypothalamus. There is certainly much evidence that this is the case. "Thalamic" cats do not feed spontaneously even though the lateral hypothalamus remains ${ }^{12}$, whereas those in which striatal and pallidal tissue, and some of the basal forebrain, also survives will actively seek food and eat it ${ }^{37}$. Aphagia is produced in rats by lesions in the globus pallidus or ansa lenticularis ${ }^{20,27}$, and feeding behavior is permanently and seriously disrupted by pallidal lesions in cats $^{29}$. Lesions in the subthalamic area, which would interrupt the pallido-tegmental projection, also produce aphagia in cats and macaques ${ }^{1}$. It is thus possible to look first to the globus pallidus for the major initiating outflow to produce feeding behavior, and consider the effective lateral hypothalamic, ventral tegmental and paragriseal points as merely lying along the pallidal projection pathway. Where the pathway lies at the A 8 and A 9 level (Fig. 2), however, is a disturbing puzzle. An equally difficult flaw in this reasoning is that synaptically active drugs affect feeding behavior when applied to the lateral hypothalamus ${ }^{15,36}$; although in the two instances tried the same result was also obtained from globus pallidus ${ }^{36}$.

The significance of the potentials evoked in frontal cortex by hypothalamic and tegmental stimuli cannot be assessed at present, but it is of interest that they were prominent in areas homologous to those from which BABKIN and VAN BUREN ${ }^{5}$ produced a variety of alimentary reactions in dogs. The strong projection of the lateral hypothalamus and ventral tegmental area into the olfactory tubercle and region of the diagonal band, seen by evoked potentials (Fig. 3), may or may not be related to feeding. Stimulation in this region can elicit alimentary reflexes in cats $^{30}$ and feeding in macaques ${ }^{31}$. Extirpation which included all of the amygdala bilaterally but also removed significant portions of globus pallidus, pyriform cortex and olfactory tubercle produced permanent aphagia in the one dog studied ${ }^{8}$. FreEMaN ${ }^{14}$ has found changes in potentials and in excitability of prepyriform cortex which are related to food deprivation or satiety in cats. Such tentative concatenations suggest experiments, but at the moment provide no definitive answers. 


\section{References}

1 ADEy, W. R., and D.F. LindsLey: On the role of subthalamic areas in the maintenance of brain-stem reticular excitability. Exp. Neurol. 1, 407-426 (1959).

2 ANAND, B.K., and J.R. BRoBECK: Hypothalamic control of food intake in rats and cats. Yale J. Biol. Med. 24, 123-140 (1951).

3 - and $\mathrm{S}$. DUA: Feeding responses induced by electrical stimulation of the hypothalamus in the cat. Indian J. med. Res. 43, 113-122 (1955).

4 - - and KAte Shoendera: Hypothalamic control of food intake in cats and monkeys. J. Physiol. (Lond.) 127, 143-152 (1955).

5 BaBkin, B.P., and J.M. VAN BUREN : Mechanism and cortical representation of the feeding pattern. A.M.A. Arch. Neurol. Psychiat. 66, 1-19 (1951).

${ }^{6}$ BignaLL, K.E.: A transistorized constant current converter. EEG Clin. Neurophysiol. 15, $702-703$ (1963).

7 BrÜGger, M.: Freßtrieb als hypothalamisches Symptom. Helv. physiol. pharmacol. Acta 1, 183-198 (1943).

8 Brotkowski, S., E. Fonberg, J. Kreiner, E. Mempel, and B. Sychowa: Aphagia and adipsia in a dog with bilateral complete lesion of the amygdaloid complex. Acta Biol. expt. 22, 43-50 (1962).

9 Delgado, J.M.R., and B.K. ANand: Increase of food intake induced by electrical stimulation of the lateral hypothalamus. Amer. J. Physiol. 72, 162-168 (1953).

10 Doty, R.W.: Conditioned reflexes formed and evoked by brain stimulation. In: Electrical Stimulation of the Brain, pp. 397-412. SHeER, D.E. (Editor). Houston: University of Texas Press 1961.

11 -, and C. Grurgea: Conditioned reflexes established by coupling electrical excitation of two cortical areas. In: Brain Mechanisms and Learning, pp. 133-151. Delafresnaym, J., A. Fessard, R.W. Gerard, and J. Konorski (Editors). London: Blackwell Scientific Publ. Ltd. 1961.

12 Emmers, R., R.W.M. Chun, and G.H. WANG: Behavior and reflexes of chronic thalamic cats. Arch. ital. Biol. 103, 178-193 (1965).

13 Foukow, B., and E.H. Rubinstenv: Behavioral and gastrointestinal changes (motility and blood flow) induced by electrical stimulation of the lateral hypothalamus in cats. Acta physiol. scand. 59, Suppl. 213, 44 (1963).

14 Freeman, W.J.: Changes in prepyriform evoked potentials with food deprivation and consumption. Exp. Neurol. 6, 12-29 (1962).

15 Grossman, S.P.: Behavioural effects of direct chemical stimulation of central nervous system structures. Int. J. Neuropharmacol. 3, 45-58 (1964).

16 Hess, W.R.: Das Zwischenhirn, 218 Seiten. Basel: Benno Schwabe \& Co. 1954.

17 Hozbel, B.G., and P. Teitelbadm: Hypothalamic control of feeding and self-stimulation. Science $135,375-376$ (1962).

18 JASPER, H.H., and C. AJMonE-MARSAN : A Stereotaxic Atlas of the Diencephalon of the Cat. National Research Council of Canada, Ottawa, Canada, 1960.

19 Johrson, T.N., and C.D. Clemente: An experimental study of the fiber connections between the putamen, globus pallidus, ventral thalamus, and midbrain tegmentum in cat. J. comp. Neurol. 113, 83-101 (1959).

${ }^{20}$ Karli, P., and M. Vergenes: Dissociation experimentale du comportment d'agression interspecifique Rat-Souris et du comportment alimentaire. C.R. Soc. Biol. Paris 143, $650-653(1964)$.

${ }^{21}$ Larsson, S.: Hyperphagia from stimulation of the hypothalamus and medulla in sheep and goats. Acta physiol. scand. 32, Suppl. 115, Pt. 1, $1-40$ (1954).

${ }^{22}$ Marre, F.W.: Eating and drinking responses elicited by diencephalic stimulation in unanesthetized rats. Fed. Proc. 15, 124 (1956).

${ }^{23}$ Margules, D.L., and J. OLDs: Identical "feeding" and "rewarding" systems in the lateral hypothalamus of rats. Science 135, 374-375 (1962).

${ }^{24}$ MILLER, N.E.: Learning and performance motivated by direct stimulation of the brain. In: Electrical Stimulation of the Brain, pp. 387-396. SHEER, D.E. (Editor). Houston: University of Texas Press 1961. 
25 Morgan, L. O.: The corpus striatum. A study of secondary degenerations following experimental lesions in cats. Arch. Neurol. Psychiat. (Chic.) 18, 495-549 (1927).

${ }^{26}$ Morgane, P.J.: Medial forebrain bundle and "feeding centers" of the hypothalamus. J. comp. Neurol. 117, 1-25 (1961).

27 - Alterations in feeding and drinking behavior of rats with lesions in globi pallidi. Amer. J. Physiol. 201, 420-428 (1961).

${ }^{28}$ - Distinct "feeding" and "hunger motivating" systems in the lateral hypothalamus of the rat. Science 133, 887-888 (1961).

${ }^{29}$ OLESHKO, N.N.: Natural and artificial motor alimentary conditioned reflexes in cats following bilateral extirpation of globus pallidus. J. Higher Nerv. Activity 14, 847-856 (1964) (Russian).

30 Rioch, D. McK., and C. Brenner: Experiments on the striatum and rhinencephalon. J. comp. Neurol. 68, 491- 507 (1938).

${ }^{31}$ Rosinson, B.W., and M. Mrshistv: Alimentary responses evoked from forebrain structures in Macaca mulatta. Science 136, 260-262 (1962).

32 Rodgers, W.L., A.N. EPSTeIn, and P. Teitelbaun: Lateral hypothalamic aphagia: motor failure or motivational deficit? Amer. J, Physiol. 208, 334-342 (1965).

${ }^{33}$ Sмттн, O.A.: Food intake and hypothalamic stimulation. In: Electrical Stimulation of the Brain, pp. 367-370. SHEER, D.E. (Editor). Houston: University of Texas Press 1961.

${ }^{34}$ Tremirly, B., and J. Sutin: Slow-wave activity in the ventral tegmental area of Tsai related to barbiturate anesthesia. Exp. Neurol. 5, 120-130 (1962).

${ }_{35}$ Tsar, T.: The optic tracts and centers of the opposum, Didelphis virginiana. J. comp. Neurol. 39, 173-216 (1925).

36 WAGNER, J.W., and J. DEGRoot: Changes in feeding behavior after intracerebral injections in the rat. Amer. J. Physiol. 204, 483-487 (1963).

37 WANG, G.H., and K. АкERT: Behavior and reflexes of chronic striatal cats. Arch. ital. Biol. 100, $48-85(1962)$.

${ }^{38}$ WIRTH, K.E.: Nahrungsaufnahme der Ratte nach Ausschaltungen und elektrischer Reizung im Hypothalamus. Pflügers Arch. ges. Physiol. 272, 602-611 (1961).

${ }^{39}$ Woodburne, R.T., E.C. Crosby, and R.E. McCotter: The mammalian midbrain and isthmus regions. Part II. The fiber connections A. The relations of the tegmentum of the midbrain with the basal ganglia in Macaca mulatta. J. comp. Neurol. 85, 67-93 (1946).

40 Wrrwicka, W., C. Dobrzecka, and R. TARnECKI: The effect of electrical stimulation of the hypothalamic feeding centre in satiated goats on alimentary conditioned reflexes, Type II. Acta Biol. exp. 20, 121-136 (1960).

11 _, and R.W. DoTY : Electrical stimulation of "feeding centers". Fed. Proc. 21, 353 (1962).

\section{Dr. Robert W. Doty}

Center for Brain Research, University of Rochester

Rochester, New York 14627 (USA)

Dr. WANDA WYRWIOKA

Department of Neurophysiology

Nencki Institute of Experimental Biology

Warsaw, Poland 